\title{
The impacts of an invasive alien plant and its removal on native bees
}

\author{
Caroline Marijke NiENHUIS, Anke Christiane DiETzSch, Jane Catherine STOUT*
}

Botany Department, School of Natural Sciences, Trinity College Dublin, Dublin 2, Ireland

Received 25 April 2008 - Revised 20 November 2008 - Accepted 2 December 2008

\begin{abstract}
Although the alien Impatiens glandulifera successfully invades riparian habitats and is visited by native insects, knowledge of its impact on native bees is limited. We assessed pollinator abundance in field sites where I. glandulifera was absent, present or had been experimentally removed. We measured insect visitation to flowers of potted native plants and to I. glandulifera. Bombus spp. comprised the highest proportion of visitors in invaded sites, whereas solitary bees made up the highest proportion in sites where I. glandulifera was removed. More bees, especially medium- and long-tongued Bombus spp. (B. pascuorum and $B$. hortorum), foraged on I. glandulifera than the native plant species (possibly because the alien was more abundant). We detected no impact of invasion on standardised pollinator abundance, B. pascuorum abundance, nor functional insect diversity, which may be due to variable climatic conditions. We suggest that future studies focus on impacts on rare or specialised pollinator taxa.
\end{abstract}

Bombus / Impatiens glandulifera / nectar secretion rate / nectar sugar concentration / Syrphidae

\section{INTRODUCTION}

Invasive species are regarded as one of the greatest threats to global biodiversity (Vitousek et al., 1997; Sala et al., 2000) as they disrupt the composition and functioning of local ecosystems (Chapin et al., 2000; Richardson et al., 2000; Levine et al., 2003) and pose serious economic and health problems (Davis, 2003). Although direct (e.g. smothering) and indirect (competition for nutrients and water) negative effects of invasive alien plants on native plant communities have been reported (Levine et al., 2003 and references therein), little is known about their direct (and indirect) effects on native pollinators (Traveset and Richardson, 2006; Bjerknes et al., 2007; Goodell, 2008).

Since they must form mutualistic interactions with pollinators already present in

Corresponding author: C.M. Nienhuis, nienhuic@tcd.ie

* Manuscript editor: Jacqueline Pierre the ecosystem in order to establish and invade (Richardson et al., 2000; Parker and Haubensak, 2002; Stout et al., 2006), entomophilous alien plants depend greatly on native pollinators for reproduction and population growth (Parker, 1997). They are more likely to be successful invaders if served by a range of generalist pollinators rather than a single specialised taxon (Richardson et al., 2000; Memmott and Waser, 2002; Johnson and Steiner, 2000; but see Morales and Aizen, 2006). Hence alien plants have the potential to directly and indirectly impact individuals, populations and communities of native generalist pollinators.

Some alien plants, particularly those that produce an abundance of large brightlycoloured flowers with extended flowering seasons, are very attractive to native pollinators (Ghazoul, 2002; Memmott and Waser, 2002). For example, Impatiens glandulifera (Balsaminaceae), Mimosa pigra (Leguminosae) and Rhododendron ponticum (Ericaceae) are regularly visited by native pollinators in the 
communities they invade (Starý and Tkalců, 1998; Chittka and Schürkens, 2001; Schürkens and Chittka, 2001; Moragues and Traveset, 2005; Stout et al., 2006; Lopezaraiza-Mikel et al., 2007). However, the nectar and pollen provided by these plants may be inappropriate for some native pollinators morphologically (pollinators may not be able to access rewards from flowers), physiologically (they may be nutritionally poor, or even contain toxins (Barker, 1978)) and phenologically (there may be temporal mis-matches between reward supply and pollinator demand). Alternatively, these plants may provide valuable resources for native pollinators, which are in decline globally (Biesmeijer et al., 2006).

If alien plant invasion causes a change in the native plant community by altering the spatial distribution of floral resources (Ghazoul, 2002) or even displacing important native plant species (Rathcke, 1983), invasive alien plants have the potential to indirectly impact both generalist and specialist taxa who utilise these native plants. It is likely that specialist species are those most at threat (see also Biesmeijer et al., 2006).

Impatiens glandulifera Royle (Balsaminaceae) is the tallest annual herb in Europe and is regarded as extremely invasive (Beerling and Perrins, 1993; Hulme and Bremner, 2006). Since its introduction from the Himalayas as a garden plant at the beginning of the 19th century (Beerling and Perrins, 1993), I. glandulifera has established, invaded and spread rapidly in riparian habitats across Europe (Perrins et al., 1993; Pyšek and Prach, 1995; Hulme and Bremner, 2006). Their frequent disturbance regimes (i.e. flooding) make riparian habitats ideal sites for I. glandulifera to invade as propagules carried by water establish easily (Pyšek and Prach, 1993; Maskell et al., 2006). Riparian habitats are one of the most diverse ecosystems worldwide (Naiman and Décamps, 1997), providing vital resources for native insects (Starý and Tkalců, 1998). I. glandulifera has been reported to interfere with such native communities by competing for (Prowse and Goodridge, 2000; Chittka and Schürkens, 2001) and facilitating (Lopezaraiza-Mikel et al., 2007) pollinator visitation to the native flora but may ben- efit native pollinators by supplying important nectar and pollen resources (Showler, 1989; Starý and Tkalců, 1998).

I. glandulifera is considered invasive in Ireland where it was first recorded in 1906 and since then has spread extensively (Reynolds, 2002). Despite much research being conducted on I. glandulifera in continental Europe (Könies and Glavač, 1979; Starý and Tkalců, 1998; Titze, 2000; Chittka and Schürkens, 2001; Hejda and Pyšek, 2006) and the UK (Lopezaraiza-Mikel et al., 2007), no study known to us in Ireland or elsewhere has quantified the impacts of I. glandulifera and its removal on native pollinators in a controlled manipulative field experiment. We tested the following hypotheses:

1. Insect abundance and functional diversity, and Bombus spp. abundance and diversity, vary between sites invaded by $I$. glandulifera compared with non-invaded sites and sites with $I$. glandulifera removed.

2. Bees preferentially visit alien (I. glandulifera) plants.

3. Nectar secretion rate and nectar sugar concentration differ between native and alien (I. glandulifera) plants and are correlated with insect visitation.

\section{METHODS}

\subsection{Study site}

This study was conducted along the River Liffey, Co. Dublin (outside the conurbation of Dublin), Ireland, between 17th July and 2nd August 2006. I. glandulifera is distributed patchily along the river, with dense patches occurring where the bank gradient is gradual and disturbed.

Nine sites (of approximately $50 \mathrm{~m} \times 15 \mathrm{~m}$ and at least $800 \mathrm{~m}$ apart) were selected along the river, three where I. glandulifera was absent and the remaining sites were randomly assigned to two treatments: I. glandulifera present (mean \pm S.E. inflorescences per site $=320 \pm 109)$ and I. glandulifera removed (mean \pm S.E. inflorescences removed per site $=358 \pm 318)$. I. glandulifera was removed by cutting inflorescences and buds from plants already in flower, at least two days before observations began and floral removal continued 
throughout the observational period to ensure the absence of alien flowers.

\subsection{Floral abundance and diversity}

After I. glandulifera removal, floral abundance and floral diversity was assessed in each site by walking a $60 \mathrm{~m}$ transect and recording the number of plant species and the total number of inflorescences per plant species within twelve $2 \mathrm{~m}^{2}$ quadrats (at $5 \mathrm{~m}$ intervals). For each site, floral diversity was calculated using the Shannon diversity index $(H)$ (Southwood and Henderson, 2000);

$\mathrm{H}=-\Sigma p_{i} \log _{e} p_{i}$, where

$p_{i}=$ proportion of total number of inflorescences present of species $i$.

One-factor Analysis of Variance (ANOVA) was used to establish whether floral diversity differed between treatments.

\subsection{Insect abundance and diversity}

To quantify insect abundance and activity we observed insect visitation rates to native plants. In order to standardise native plant abundance and density, we introduced 18 native plants in pots, six individuals of each of three native species (Epilobium hirsutum (Onagraceae), Filipendula ulmaria (Rosaceae) and Stachys palustris (Lamiaceae)) into each site. These species were chosen because they are widespread in the section where the experiment was conducted along the River Liffey, flower simultaneously with I. glandulifera, are frequently visited by insects (Fussell and Corbet, 1992; Comba et al., 1999) and have been used in previous studies (Chittka and Schürkens, 2001; Lopezaraiza-Mikel, 2006). In invaded sites, plants were placed directly next to I. glandulifera patches. A small proportion $(<10 \%)$ of potted plants failed to flower and therefore plants in flower were cut from naturally established stands located outside the sites and placed into water-filled bottles in order to maintain the number of flowering plants in the standard artificial native plant communities. Where necessary, plants were substituted at least one day before observations commenced. Each site was visited once, between 8.00 to $18.00 \mathrm{hrs}$, on each of three separate days during the period between 17th July and 25 th July 2006. On each visit, a total of six plants (two of each of the three native species) were observed for 10 minutes. In addition three randomly selected I. glandulifera patches were observed for 10 minutes in each of the invaded sites. All insects visiting flowers for nectar and/or pollen were identified to family (Andrenidae, Apidae and Syrphidae) and social bees to species (Bombus spp. and Apis mellifera). Andrenids and syrphids were difficult to identify to species on the wing, and we did not want to capture individuals (because we did not want to affect either their behaviour or their populations). The total number of inflorescences per plant species per patch was recorded after observations. Standardised insect abundance was calculated as the number of insects per inflorescence per hour (number of insects arriving at a patch in $10 \mathrm{~min} /$ number of inflorescences in patch $\times 6$ ). In addition, temperature $\left({ }^{\circ} \mathrm{C}\right)$, cloud cover $(\%)$ and wind force (Beaufort scale) were recorded during each observation session.

Although insect visitation does not provide a direct measure of insect abundance, other methods such as pan traps were considered too destructive to the insect community. Transect walks were not employed because of variation in native plant communities among sites.

Total standardised insect abundance (analysed separately for all insects, all bees including Bombus spp., syrphids and Bombus spp.) on native and alien inflorescences were compared among treatments and sites using a balanced two-factor nested Analysis of Covariance (ANCOVA) ('site' as random factor nested within 'treatment' as fixed factor) with temperature, cloud cover and wind force as covariates. Cloud cover (proportional data) and wind force (count data) data were arcsine and square root transformed respectively. ANCOVAs were also performed on non-normal data as analysis of variance is robust to non-normality (Underwood, 1997). Levene's test was used to test for heterogeneity of variances and if necessary data were $\log _{10}(\mathrm{x}+1)$ transformed (syrphid and total insect abundance). When transformations were unable to reduce heterogeneity of variances, non-parametric analysis (Mood's Median test) was employed. In addition, we investigated whether insect abundance differed between I. glandulifera and the three native plant species in invaded sites, using one-factor ANOVA and a Dunnett's post-hoc test. A post-hoc power analysis was conducted using total standardised insect abundance.

Because of difficulties in identifying some insects to species (see above), insects were assigned to five functional groups (andrenids, syrphids, long- and medium-tongued Bombus spp. 
(B. hortorum and B. pascuorum), short-tongued Bombus spp. (B. pratorum and B. terrestris) and $A$. mellifera. Insect diversity for each site was estimated using the Shannon diversity index $(H)$ (as above).

To test for differences in insect diversity among treatments, data were analysed with one-factor ANOVA as above.

\subsection{Bombus spp. abundance and diversity}

To estimate bumblebee abundance in, and utilisation of, all nine sites, we conducted markrecapture studies between 26th July and 2nd August 2006, during the removal period after observations on native plants had taken place. B. pascuorum was selected as study species because it was the most commonly observed insect visitor in these sites. Each site was visited twice. On the first visit, all $B$. pascuorum individuals encountered during a 1.5 hour period were captured, their thorax marked with red permanent marker and released. Observations on freely foraging bumblebees from colonies kept in captivity have shown that marks on the thorax are clearly visible for up to five days (A. Dietzsch, unpubl. data.). Studies of the foraging range of $B$. pascuorum suggest that the same individuals are unlikely to occur at multiple sites when they are $>800 \mathrm{~m}$ apart (Darvill et al., 2004; Knight et al., 2005). Twenty-four hours later, sites were revisited and all bumblebees encountered were caught and the number of marked and unmarked individuals recorded. The number of B. pascuorum per site was estimated according to the Lincoln-Peterson formula $(N)$ (Southwood and Henderson, 2000);

$N=\left(\mathrm{n}_{1} \times \mathrm{n}_{2}\right) / \mathrm{m}_{2}$, where

$\mathrm{n}_{1}=$ total number of B. pascuorum caught and marked in first sample,

$\mathrm{n}_{2}=$ total number of $B$. pascuorum caught in second sample,

$\mathrm{m}_{2}=$ number of marked B. pascuorum recovered in second sample.

To estimate Bombus spp. diversity in each site, we used the number of individuals for each Bombus spp. (B. hortorum, B. pascuorum, B. pratorum and $B$. terrestris) visiting native and alien patches recorded during observations. For each treatment Bombus spp. diversity was estimated using the Shannon diversity index $(H)$ (as above).

To determine whether Bombus spp. numbers and diversity differed between treatments, data were analysed using one-factor ANOVA as above.

\subsection{Nectar resources}

Immediately after observations of insect visitation, nectar standing crop was determined at each site in 10 randomly selected flowers of all plant species that had been visited by bumblebees, using 1 and $5 \mu \mathrm{L}$ micropipettes (Hirschmann Laborgeräte $\mathrm{GmbH} \&$ Co.KG, Eberstadt, Germany). In addition, nectar secretion rate (per 24 hours) and sugar concentrations for each study plant species visited by bumblebees were determined at each site by randomly bagging ten flowers per species with bridal veil material to exclude insect visitors. A hand-held refractometer (Ceti-Digit-080, Medline Scientific Ltd, Oxfordshire, UK) was used to measure sugar concentration. We excluded $F$. ulmaria from nectar measurements because flowers were too small to extract any measurable nectar quantities, even after bagging.

The relationship between nectar standing crop and insect abundance was investigated using correlations. Pearson's product moment correlation was utilised for all data related to I. glandulifera (parametric) and Spearman's rank correlation was employed for data related to E. hirsutum and S. palustris (non-parametric). One-factor ANOVAs were used to examine whether nectar sugar concentrations and secretion rates differed between I. glandulifera and the native plant species. Data for nectar secretion rates were $\log _{10}(\mathrm{x})$ transformed to reduce heterogeneity of variance. Dunnett's post-hoc tests were utilised to compare sugar concentrations and secretion rates between the three species.

MINITAB 13 (Minitab, 2000) was used for all statistical analyses.

\section{RESULTS}

\subsection{Floral abundance and diversity}

The co-flowering vegetation in the sites contained a species rich assemblage of native plants and included Calystegia sepium (Convolvulaceae), Chamaenerion angustifolium (Onagraceae), Cirsium palustre (Asteraceae), Epilobium hirsutum (Onagraceae), Eupatorium cannabinum (Asteraceae), Filipendula ulmaria (Rosaceae), Rubus fruticosus agg (Rosaceae), Scrophularia aquatica (Scrophulariaceae), Senecio jacobaea (Asteraceae), and Stachys palustris (Lamiaceae). Neither floral 


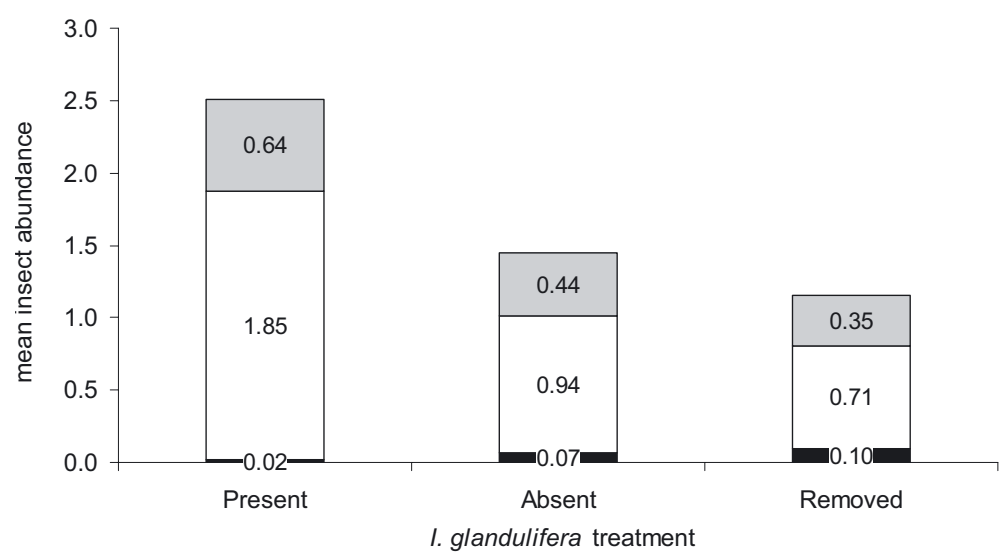

Figure 1. Mean insect abundance (standardised as insects per inflorescence per hour) on native inflorescences made by Bombus spp., other Hymenoptera and Syrphidae in sites where I. glandulifera was present, absent and had been experimentally removed. Bombus spp. (grey bars), Syrphidae (open bars), and other Hymenoptera (closed bars).

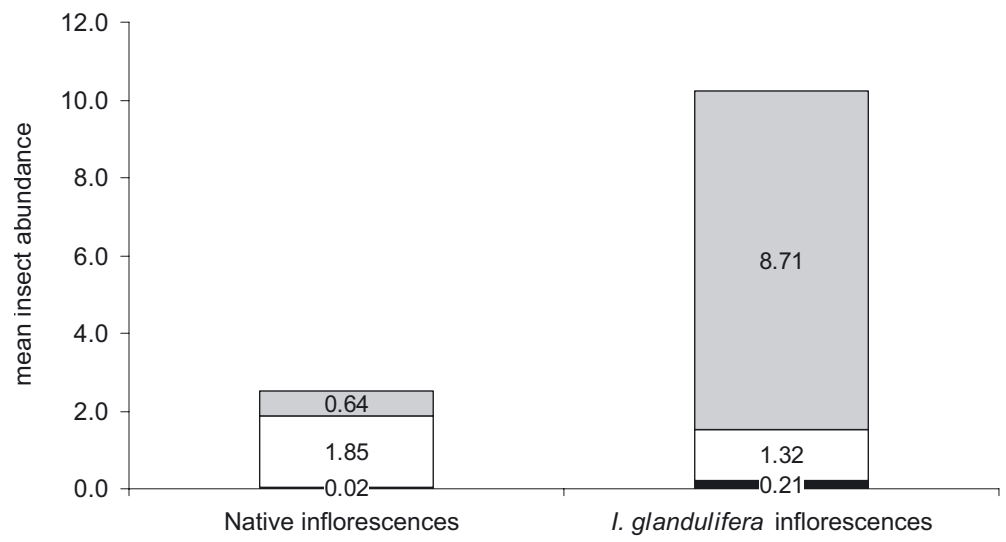

Figure 2. Mean insect abundance (standardised as insects per inflorescence per hour) on native versus $I$. glandulifera inflorescences made by Bombus spp., other Hymenoptera and Syrphidae in sites where I. glandulifera was present. Bombus spp. (grey bars), Syrphidae (open bars), and other Hymenoptera (closed bars).

abundance $\left(F_{2,8}=0.86, P>0.05\right)$ nor floral diversity $(H$ ranging from 0.96 to 1.70 ; $\left.F_{2,8}=0.61, P>0.05\right)$ differed significantly among treatments, probably due to high variation among sites within treatments.

\subsection{Insect diversity}

In 360 observation minutes, a total of 263 individual insects were observed visiting native potted plants (138 Hymenoptera and 125 Diptera). Sites containing I. glandulif- era attracted more flower visitors (12.75 individuals per inflorescence per hour) than non-invaded sites (I. glandulifera absent $=$ 1.45 individuals per inflorescence per hour; I. glandulifera removed $=1.16$ individuals per inflorescence per hour). Both Bombus spp. and syrphids seemed to be more abundant on native inflorescences in invaded compared to non-invaded sites (Fig. 1), with Bombus spp. being especially abundant on I. glandulifera inflorescences in sites where the alien was present (Fig. 2). However, syrphids made up higher proportions of flower visitors in sites 


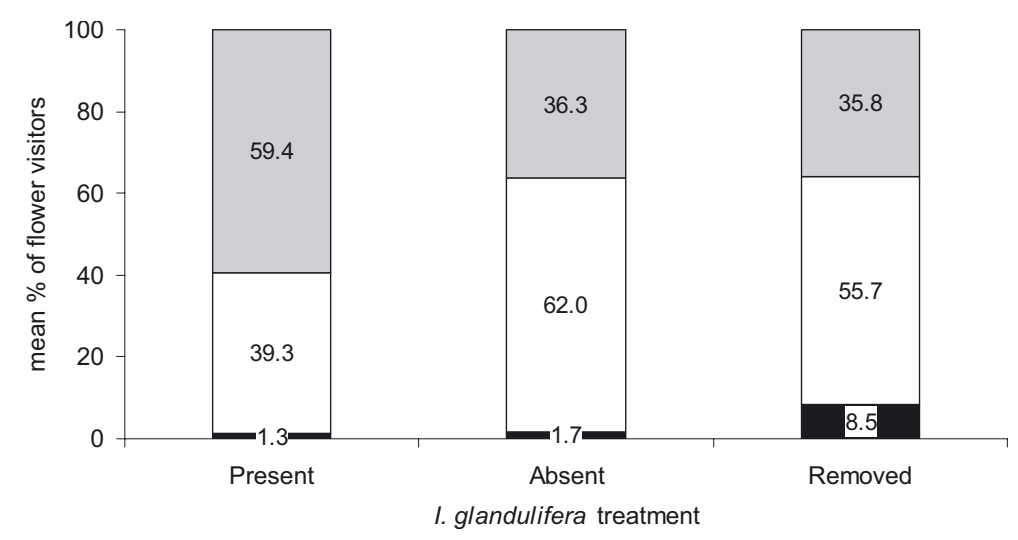

Figure 3. Mean percentage of flower visitors to native and alien inflorescences made by Bombus spp., other Hymenoptera and Syrphidae in sites where I. glandulifera was present, absent and had been experimentally removed. Bombus spp. (grey bars), Syrphidae (open bars), other Hymenoptera (closed bars).

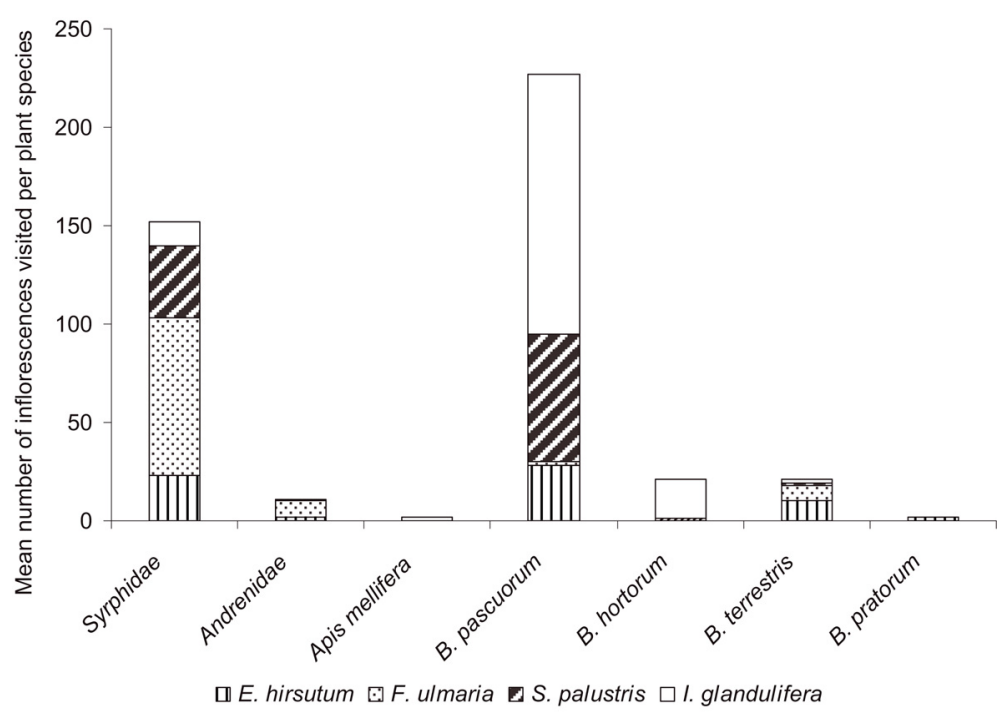

Figure 4. Mean number of native and alien inflorescences visited by each insect taxa.

without I. glandulifera whereas Bombus spp. comprised a higher proportion in invaded sites (Fig. 3). Other bees only constituted a minority of visitors, including Andrena spp. (seven visitors) and A. mellifera (one visitor), and made up a higher proportion of visitors when I. glandulifera was removed (Fig. 3). Bombus spp. visitors included medium-tongued B. pascuorum (112 visitors), long-tongued $B$. hortorum (10 visitors), short-tongued $B$. terrestris (eight visitors) and short-tongued $B$. pratorum (one visitor).
The different plant species attracted different pollinator groups: syrphids more frequently visited $F$. ulmaria, thereafter S. palustris, E. hirsutum and, rarely, I. glandulifera. In contrast, bees primarily visited I. glandulifera followed by $S$. palustris, E. hirsutum and, rarely, F. ulmaria, except andrenids which mainly visited $F$. ulmaria (Fig. 4). B. pascuorum was the most frequent Bombus spp. recorded and many of this species' visits were to I. glandulifera. $B$. hortorum chiefly visited I. glandulifera 
Table I. Insect abundance on native plants [N], and on native versus alien plants in invaded sites [N vs. A], standardised as insects per inflorescence per hour, compared among treatments [T] and sites (nested within treatments $\mathrm{S}[\mathrm{T}]$ ) using parametric tests (ANCOVA $F$ and ANOVA $F$ ) and non-parametric tests (Mood's Median $X^{2}$ ). "Bee" = all bees including Bombus spp. Covariates include temperature (TP), cloud cover (CC) and wind force (WF). ns $=$ non-significant results, $* P<0.05, * * P<0.001$.

\begin{tabular}{cccccc}
\hline & & Total insect & Bee & Bombus spp. & Syrphids \\
\hline $\mathrm{N}$ & $\mathrm{T}$ & $F_{2,26}=0.19 \mathrm{~ns}$ & $F_{2,26}=0.69 \mathrm{~ns}$ & $F_{2,26}=1.07 \mathrm{~ns}$ & $F_{2,26}=0.48 \mathrm{~ns}$ \\
& $\mathrm{~S}(\mathrm{~T})$ & $F_{6,26}=4.61 \mathrm{~ns}$ & $F_{6,26}=1.15 \mathrm{~ns}$ & $F_{6,26}=1.09 \mathrm{~ns}$ & $F_{6,26}=2.26 \mathrm{~ns}$ \\
& $\mathrm{TP}$ & $F_{1,26}=7.09 *$ & $F_{1,26}=0.25 \mathrm{~ns}$ & $F_{1,26}=0.33 \mathrm{~ns}$ & $F_{1,26}=1.67 \mathrm{~ns}$ \\
& $\mathrm{CC}$ & $F_{1,26}=12.80 *$ & $F_{1,26}=1.68 \mathrm{~ns}$ & $F_{1,26}=3.09 \mathrm{~ns}$ & $F_{1,26}=0.63 \mathrm{~ns}$ \\
& WF & $F_{1,26}=1.16 \mathrm{~ns}$ & $F_{1,26}=0.16 \mathrm{~ns}$ & $F_{1,26}=0.21 \mathrm{~ns}$ & $F_{1,26}=0.45 \mathrm{~ns}$ \\
N vs. A & & $F_{1,17}=16.01 *$ & $X_{1}^{2}=18 * *$ & $X_{1}^{2}=18 * *$ & $F_{1,17}=0.29 \mathrm{~ns}$ \\
\hline
\end{tabular}

inflorescences, whereas $B$. terrestris visited native plants more often. Bombus spp. visited all plants primarily for nectar, except for $F$. ulmaria where Bombus spp. collected pollen only (they were not observed to extend their probosces for nectar collection).

The functional diversity of insects ( $H$ ranging from 0.54 to 1.08$)$ did not vary among treatments $\left(F_{2,8}=0.42 ; P=0.676\right)$.

\subsection{Insect abundance}

Analysis of standardised insect abundance on native plants revealed no significant differences among treatments with only total insect abundance varying between sites (Tab. I). During observations there was a mean $( \pm$ S.E.) temperature of $23.1 \pm 2.9{ }^{\circ} \mathrm{C}$ and mean ( \pm S.E.) cloud cover of $49 \pm 40 \%$. Total insect abundance was influenced negatively by cloud cover and temperature whereas bee, Bombus spp. and syrphid abundances remained unaffected by the environmental variables (Tab. I). Abundance, if visitors to both native and alien plants are considered, differed between sites within treatments $\left(F_{6,26}=3.94, P<0.05\right)$ but not between the three treatments $\left(F_{2,26}=0.40\right.$, $P>0.05)$. There was no significant difference in the number of bees and the number of syrphids recorded visiting native plants overall $\left(F_{1,53}=3.84, P>0.05\right)$. In sites where I. glandulifera was present, significantly more insects (except syrphids) were observed on alien I. glandulifera than on native plants (Tab. I) and significantly more bees were observed visiting I. glandulifera than syrphids
$\left(F_{1,17}=24.37, P<0.001\right)$. In these sites, insect abundance was significantly higher on I. glandulifera than native $E$. hirsutum and $S$. palustris $\left(F_{3,35}=6.02, P<0.05\right.$; Dunnett's post-hoc test $P<0.05)$, but there were no differences between I. glandulifera and $F$. ulmaria (Dunnett's post-hoc test $P>0.05$ ).

We detected low power $(\alpha=0.065)$ for the analysis on total insect abundance (three sites per treatment), and increasing the number of sites per treatment by a factor of ten $(\mathrm{N}=30)$ did not increase power greatly $(\alpha=0.319)$.

\subsection{Bombus spp. abundance and diversity}

The mean total number ( \pm S.E.) of B. pascuorum individuals caught and marked in first sample $\left(\mathrm{n}_{1}\right)$ and subsequently caught in second sample $\left(\mathrm{n}_{2}\right)$, and the mean number ( \pm S.E.) of marked $B$. pascuorum individuals recovered in second sample $\left(\mathrm{m}_{2}\right)$ for each treatment were: I. glandulifera absent: $15.3 \pm 7.4,18.7 \pm 5.8$ and $6.3 \pm 2.3$, I. glandulifera removed: $7.0 \pm 2.6,10.0 \pm 4.0$ and $3.3 \pm 1.8$, I. glandulifera present: $41.7 \pm 11.3$, $42.0 \pm 10.7$ and $31.7 \pm 9.4$, respectively. Overall, mean values of $N$ (estimates of abundance according to the Lincoln-Peterson formula, calculated per site and averaged per treatment) suggested that there were fewer $B$. pascuorum individuals in sites where I. glandulifera was removed (Fig. 5), although this difference was not significant ( $N$ ranging from 0 to 76; $\left.F_{2,8}=2.11, P>0.05\right)$. There were no significant differences in Bombus species diversity 


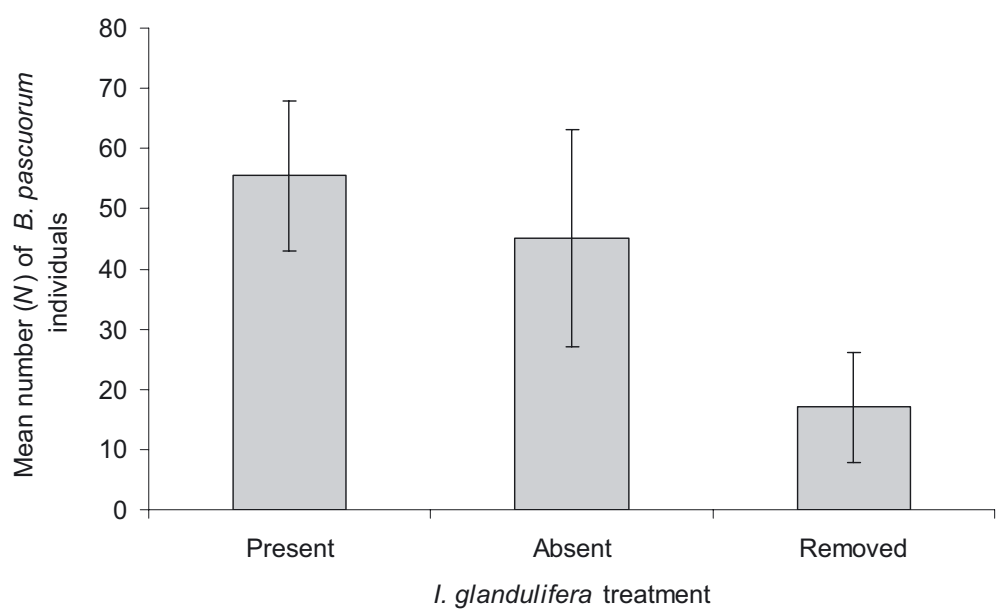

Figure 5. Mean value of $\mathrm{N}$ (estimated using the Lincoln-Peterson formula) for B. pascuorum individuals in sites where I. glandulifera was present, absent and had been experimentally removed.

Table II. Nectar standing crop $(\mu \mathrm{L})$, nectar secretion rate $(\mu \mathrm{L} / 24 \mathrm{hrs})$ and nectar sugar concentration $(\%)$ of native (Epilobium hirsutum and Stachys palustris) and alien (Impatiens glandulifera) plant species (mean \pm S.E.).

\begin{tabular}{lccc}
\hline Plant species & Nectar standing crop & Nectar secretion rate & Nectar sugar concentration \\
\hline E. hirsutum & $0.054 \pm 0.007$ & $0.502 \pm 0.072$ & $47.1 \pm 1.4$ \\
S. palustris & $0.011 \pm 0.003$ & $0.167 \pm 0.049$ & $47.1 \pm 1.1$ \\
I. glandulifera & $0.043 \pm 0.016$ & $10.619 \pm 2.176$ & $53.9 \pm 2.2$ \\
\hline
\end{tabular}

among treatments $(H$ ranging from 0.00 to $\left.0.95 ; F_{2,8}=0.13, P>0.05\right)$.

\subsection{Nectar resources}

When flowers were bagged to prevent insect visitation, nectar was found in native E. hirsutum and S. palustris species and alien I. glandulifera. Mean nectar standing crop was low in all plant species (Tab. II). No significant correlation was found between insect abundance and nectar standing crop in E. hirsutum $(r=0.263, P>0.05), S$. palustris $(r=0.073$, $P>0.05)$ or I. glandulifera $(r=-0.564$, $P>0.05)$.

Mean nectar secretion rate was significantly larger in I. glandulifera than in E. hirsutum and $S$. palustris $\left(F_{2,20}=24.51, P<0.001\right.$; Dunnett's post-hoc test $P<0.05$ for both comparisons; Tab. II). Mean sugar concentration was higher in I. glandulifera compared with both E. hirsutum and S. palustris $\left(F_{2,20}=4.36\right.$,
$P<0.05$; Dunnett's post-hoc test $P<0.05$ for both comparisons; Tab. II).

\section{DISCUSSION}

Knowledge on the impacts of invasive alien plants on native pollinators is limited and our study is among the first to explicitly address this topic. We observed that the presence and/or removal of I. glandulifera did not seem to affect insect abundance or diversity although in invaded sites the alien attracted large numbers of bees, especially generalist Bombus spp. which could be due to its highly rewarding nectar resources. Here, we discuss the implications of our findings for native pollinators, in particular bees, and make suggestions for further study.

\subsection{Insect diversity}

The large, brightly-coloured flowers of I. glandulifera have been previously shown 
to attract a range of generalist insects (Fussell and Corbet, 1992; Titze, 2000; Lopezaraiza-Mikel et al., 2007). We found no differences in insect functional diversity among invaded and non-invaded sites suggesting that $I$. glandulifera does not reduce diversity at the site level. However, we did not identify solitary bees and syrphids to species, and grouping may mean we missed changes in some rare and/or specialist taxa. Bombus spp. were the most common visitors to I. glandulifera, whilst syrphids visited native plants more often. This supports similar findings from the UK (Lopezaraiza-Mikel et al., 2007). This is unsurprising considering the differences in floral morphology between two of the native plants ( $F$. ulmaria and E. hirsutum have radially symmetrical flowers) and I. glandulifera (zygomorphic flowers) and may explain Bombus spp. preference for the alien, as bees favour the latter shape (Proctor et al., 1996). I. glandulifera could be less attractive to syrphids because they are too small to access nectar in the spur located at the posterior of the lower sepal (Titze, 2000).

Bombus flower preferences varied among species, which may be explained by tongue length and corolla depths (Inouye, 1980; Prýs-Jones and Corbet, 1991; Comba et al., 1999): medium- and long-tongued Bombus spp. (B. pascuorum and B. hortorum) favoured the deep I. glandulifera flowers and shorttongued Bombus spp. (B. terrestris and B. pratorum) the more shallow native flowers. Short-tongued Bombus spp. might not be able to extract nectar from I. glandulifera, or it may take them longer, reducing their energetic gain (Harder, 1983). I. glandulifera may therefore be providing a nectar resource mainly for longer-tongued Bombus spp. Additionally, even though pollen is readily accessible to visiting insects, no visitors (both bees and syrphids) were observed actively collecting pollen during the experimental period.

\subsection{Insect abundance}

Our results suggest that the presence of I. glandulifera did not affect insect abundance, when measured as visitation to native co-flowering plant species. This finding contrasts with Lopezaraiza-Mikel et al. (2007) who observed a higher insect abundance in sites containing I. glandulifera. There may be several explanations for this. Firstly, our data were collected as visitation rates, whereas Lopezaraiza-Mikel et al. (2007) measured insect abundance using transect methods. Secondly, our study was conducted during a short time period when all potted native species and I. glandulifera were co-flowering and may not reflect the situation at other times of the year. Thirdly, we only had three sites per treatment and high within-treatment variation among plots, which may have reflected variable climatic conditions, since insect abundance decreased with increased cloud cover and temperature. We were unable to completely standardise climatic conditions due to logistical (number of observers) and temporal constraints (flowering period of plants). Indeed, small scale variability in weather is a standard source of variation in field experiments of this sort. Power analysis suggested that increasing the number of sites per treatment may not enhance experimental power and would simultaneously increase the spatial scale of the experiment, and may introduce further variation among sites. Fourthly, invaded sites attracted a higher proportion of bees, and most of these bees (principally $B$. pascuorum) preferentially visited the alien. Therefore, the abundance of insects, as recorded as visitation to native plants, did not vary since native plants still attracted other visitors (such as short-tongued Bombus spp. and syrphids) which tended not to visit I. glandulifera. Lastly, in our sites, isolated I. glandulifera patches did not occupy extensive areas of the river bank common elsewhere in Europe (Beerling and Perrins, 1993; Pyšek and Prach, 1995), and left enough space for the persistence of native plants, which represented an attractive resource to insects, particularly those less able to, or efficient at, exploiting I. glandulifera.

\subsection{Bombus spp. abundance and diversity}

Contrary to our hypothesis, invaded sites did not attract a greater abundance of 
B. pascuorum or diversity of Bombus spp. compared with non-invaded sites. Study sites contained a diverse native flora, which did not vary significantly among sites, with many valuable forage plants including Epilobium hirsutum, Rubus fruticosus agg and Cirsium spp. that provide forage resources for a variety of Bombus species (Fussell and Corbet, 1992). We can assume that the abundance of shorter-tongued Bombus species (e.g. B. terrestris) may not be influenced greatly by $I$. glandulifera as they did not utilise the alien frequently. However, if the invasion by I. glandulifera becomes more widespread, causing a loss of the native flora, we might see quite different results (c.f. Lopezaraiza-Mikel et al., 2007).

Although we only sampled during a short time period, with its prolonged flowering season (June to October), I. glandulifera may support the survival and reproduction of B. pascuorum colonies which persist until late October, when flowering native plants become scarce (Sowig, 1989; Starý and Tkalců, 1998) and queens build up fat bodies in preparation for hibernation (Prýs-Jones and Corbet, 1991). Then again, I. glandulifera provides no resources to initial queens emerging in spring and could be displacing important early flowering resources (Lopezaraiza-Mikel et al., 2007). I. glandulifera is probably less valuable to early emerging and short-tongued species with short colony cycles, such as $B$. pratorum. The impact of alien plants on the entire Bombus colony cycle and on Bombus populations and colony sizes merits further investigation and studies addressing this are currently being undertaken in Ireland (Dietzsch and Stout, in prep.).

I. glandulifera is common in disturbed habitats, which support more widespread generalist Bombus spp. such as B. terrestris and $B$. pascuorum. As a result, I. glandulifera might be a vital forage resource for and may be supporting increased populations of common generalist medium- and long-tongued Bombus spp., which have been recognised as important for conservation (Fitzpatrick et al., 2007), especially in built-up areas of Ireland. However, the possible spread of I. glandulifera into rare habitats and the consequent displacement of native plants may have severe implications on the survival of threatened bee species in Ireland.

\subsection{Nectar resources}

We observed no relationship between nectar standing crop and insect abundance. Standing crop was low in all study plants. This has been reported elsewhere (Comba et al., 1999) and may be due to low nectar secretion rates of native plants, Bombus spp. efficiently depleting resources and/or high ambient temperatures (up to $28.5^{\circ} \mathrm{C}$ in the shade) causing water to evaporate more quickly.

I. glandulifera produced significantly more nectar (20 and 81 times respectively) that was higher in sugar concentration compared to both E. hirsutum and $S$. palustris. However, native species were rooted in pots whilst I. glandulifera plants were naturally rooted in the soil, which may bias these results. Nevertheless, similarly low nectar secretion rates and sugar concentrations have been measured for naturally established plants of both $E$. hirsutum $(0.489 \pm 0.074 \mu \mathrm{L}$ and $13.7 \pm 1.5 \%$ respectively) and $S$. palustris $(1.162 \pm 0.222 \mu \mathrm{L}$ and $36.0 \pm 2.6 \%$ respectively) (Nienhuis and Stout, in prep.). Bombus spp. prefer nectarrich flowers (Heinrich, 1976; Corbet et al., 1984) with high sugar concentrations (Corbet et al., 1979) and they require energetically high rewards to maintain colonies (Comba et al., 1999; Titze, 2000; Morales and Aizen, 2006). It is unclear however, whether the quality of I. glandulifera nectar and pollen is nutritionally adequate for Bombus spp. and their colonies and current research is addressing this issue (Nienhuis and Stout, in prep.).

\subsection{I. glandulifera removal}

Our study implies that I. glandulifera flower removal had no effect on insect abundance nor did it impact $B$. pascuorum numbers and Bombus spp. diversity. In contrast, Lopezaraiza-Mikel et al. (2007) found significant reductions in both species richness and insect abundance when the alien was removed 
compared to when it was present. Alien flower removal might not have severely impacted insect abundance in our study sites because insects feeding on I. glandulifera switched to native plants instead. This is unlikely however, as the alien attracted mainly large bees (Bombus spp.) and other insects are therefore not likely to be impacted greatly. In addition, alien flower removal might not have impacted insect abundance in our study sites severely because the alien formed small patches compared to Lopezaraiza-Mikel et al.'s (2007) sites that were all heavily invaded and where I. glandulifera was the dominant plant. This suggests that pollinators were not deterred from returning to sites and were able to locate alternative forage resources rapidly after alien removal. Other studies also suggest that localised control of alien plants does not impact pollinator activity (Aigner, 2004) and species diversity is quick to recover following removal (Hejda and Pyšek, 2006). These findings imply that removing small patches of I. glandulifera flowers in order to prevent the alien from setting seed might be feasible for conservation purposes on a local scale. However, further research is needed to investigate what impacts removing monospecific and widespread stands on a regional scale has on pollinators with different life history strategies relying solely on I. glandulifera, on specialised and rare pollinator taxa and the native plant community supporting such pollinators.

\section{CONCLUSIONS}

Medium- and long-tongued Bombus spp. are utilising the sugar-rich nectar of I. glandulifera. However, it is unclear whether Bombus spp. are actively employing I. glandulifera pollen for colony maintenance and whether the pollen is nutritionally adequate. Although localised I. glandulifera flower removal does not seem to affect insect abundance, our study highlights the need for further experimental long-term studies focusing on pollinator population responses to the spread and consequent removal of I. glandulifera, especially on a regional scale.

\section{ACKNOWLEDGEMENTS}

We thank Caroline Byrne for assistance in the field, and Karl Duffy for helpful discussions. We are grateful to Dave Goulson, Karl Duffy and two anonymous referees for comments on the manuscript. This study was funded by the Irish Government (Department for the Environment and Local Government) via an Environmental Protection Agency Postgraduate Studentship (2005PHD5-B-17) provided under the Environmental Research Technological Development and Innovation (ERTDI) Programme as part of the National Development Plan 2000-2006, which was awarded to JCS and supported the PhD of CMN.

Impacts de l'introduction puis de l'élimination d'une plante invasive étrangère sur les abeilles indigènes.

Bombus / Impatiens glandulifera / plante invasive / plante introduite / secrétion nectarifère / concentration en sucres / nectar / pollinisateur / diversité écologique / abondance écologique

Zusammenfassung - Die Auswirkungen der Einschleppung und der anschließenden Beseitigung einer Neophyte auf einheimische Bienen. Die Kenntnis über die Auswirkungen von Neophyten auf die einheimischen bestäubenden Insekten ist äuBerst gering. Einige invasive Pflanzen haben auffällige florale Kennzeichen, eine hohe Nektarsekretion und sind daher attraktiv für einheimische Insekten. Eine dieser Arten ist Impatiens glandulifera, die sich erfolgreich in Flussauen von ganz Europa verbreitet hat und deren Effekte auf die einheimische Flora recht gut untersucht sind. Wir wissen allerdings wenig über direkte oder indirekte Auswirkungen von I. glandulifera auf einheimische Bestäuber. Wir erfassten die Abundanz von Bestäubern in Untersuchungsgebieten, in denen I. glandulifera vorkam bzw. nicht vorkam und in Gebieten, in denen I. glandulifera experimentell entfernt wurde. An jedem Standort legten wir nach einem standardisierten Muster Pflanzengesellschaften aus drei einheimischen Arten an und erfassten die Insektenbesuche an diesen Pflanzen. Zusätzlich erfassten wir die Besuche an I. glandulifera und führten Experimente zur Wiederfindung markierter Bombus pascuorum durch, um die Nutzung der Standorte durch Hummeln zu beurteilen. Die Anwesenheit und/oder die Entfernung von I. glandulifera hatte weder auf die standardisierte Abundanz von Insekten noch auf die funktionelle Insektendiversität einen signifikanten Einfluss (Tab. I), was eventuell auf die unterschiedlichen klimatischen Bedingungen zurück zu führen ist. Allerdings scheinen 
Bombus spp. den höchsten Anteil an Besuchen an Standorten mit Neophyten zu haben während Solitärbienen den höchsten Anteil an Standorten ausmachten, an denen I. glandulifera entfernt wurde (Abb. 3). Darüber hinaus waren Bombus spp. an den entsprechenden Standorten besonders häufig an Blütenständen von $I$. glandulifera zu finden, wobei mittel- und langrüsselige Hummeln (Bombus pascuorum und $B$. hortorum) die Neophyte bevorzugt besuchten (Fig. 4). Allerdings lockten Standorte mit $I$. glandulifera nicht mehr B. pascuorum an als Neophyten-freie Standorte (Abb. 5) und auch die Diversität von Bombus spp. unterschied sich nicht zwischen "befallenen" und "nicht befallenen" Standorten. Trotzdem macht die hohe Produktion von zuckerreichem Nektar (Tab. II) I. glandulifera zu einer äußerst attraktiven Nektarquelle für die einheimischen mittel- und langrüsselige Hummeln in Irland. So mögen die Generalisten unter den Hummelarten, die eine wichtige Bedeutung für die Bestäubung haben, durch I. glandulifera als alternative Trachtquelle letztendlich sogar unterstützt werden. Andererseits werden bereits gefährdete Bestäuber durch Neophyten eventuell zusätzlich bedroht, da einheimische Pflanzen verdrängt werden. Unsere Ergebnisse lassen darauf schließen, dass die Entfernung von kleinen Ansammlungen von I. glandulifera-Pflanzen für örtlich begrenzte Naturschutzmaßnahmen Sinn macht. Es ist aber unklar, welche Auswirkungen die Entfernung von I. glandulifera an größeren Monokultur-Standorten für Hummeln und diejenigen Bestäuber hat, die diese Balsaminenart als alleinige Trachtquelle nutzen. In Langzeitstudien sollte daher untersucht werden, wie Bestäuberpopulationen auf die Verbreitung und auf die konsequente Entfernung von I. glandulifera reagieren.

\section{Bombus / Impatiens glandulifera / Nektar- Sekretionsrate / Nektar-Zuckerkonzentration / Syrphidae}

\section{REFERENCES}

Aigner P.A. (2004) Ecological and genetic effects on demographic processes: pollination, clonality and seed production in Dithyrea maritima, Biol. Conserv. 116, 27-34.

Barker R.J. (1978) Poisoning by plants, in: Morse R.A. (Ed.), Honey bee pests, predators, and diseases, Cornell University Press, London, pp. 275-296.

Beerling D.J., Perrins J.M. (1993) Impatiens glandulifera Royle (Impatiens roylei Walp.), J. Ecol. 81, 367-382.

Biesmeijer J.C., Roberts S.P.M., Reemer M., Ohlemueller R., Edwards M., Peeters T., Schaffers A.P., Potts S.G., Kleukers R., Thomas C.D., Settele J., Kunin W.E. (2006) Parallel declines in pollinators and insect-pollinated plants in Britain and the Netherlands, Science 313, 351-354.

Bjerknes A.L., Totland Ø., Hegland S., Nielsen A. (2007) Do alien plant invasions really affect pollination success in native plant species? Biol. Conserv. 138, 1-12.

Chapin F.S., Zavaleta E.S., Eviner V.T., Naylor R.L., Vitousek P.M., Reynolds H.L., Hooper D.U., Lavorel S., Sala O.E., Hobbie S.E., Mack M.C., Diaz S. (2000) Consequences of changing biodiversity, Nature 405, 234-242.

Chittka L., Schürkens S. (2001) Successful invasion of a floral market, Nature 411, 653 .

Comba L., Corbet S.A., Hunt L., Warren B. (1999) Flowers, nectar and insect visits: evaluating British plant species for pollinator-friendly gardens, Ann. Bot. 83, 369-383.

Corbet S.A., Kerstlake C.J.C., Brown D., Morland N.E. (1984) Can bees select nectar-rich flowers in a patch? J. Apic. Res. 23, 234-242.

Corbet S.A., Unwin D.M., Prys-Jones O.E. (1979) Humidity, nectar and insect visits to flowers, with special reference to Crataegus, Tilia and Echium, Ecol. Entomol. 4, 9-22.

Darvill B., Knight M.E., Goulson D. (2004) Use of genetic markers to quantify bumblebee foraging range and nest density, Oikos 107, 471-478.

Davis M.A. (2003) Biotic globalization: Does competition from introduced species threaten biodiversity?, BioScience 53, 481-489.

Fitzpatrick U., Murray T.E., Paxton R.J., Breen J., Cotton D., Santorum V., Brown M.J.F. (2007) Rarity and decline in bumblebees - a test of causes and correlates in the Irish fauna, Biol. Conserv. 136, 185-194.

Fussell M., Corbet S.A. (1992) Flower usage by bumblebees - a basis for forage plant management, J. Appl. Ecol. 29, 451-465.

Ghazoul J. (2002) Flowers at the front line of invasion? Ecol. Entomol. 27, 638-640.

Goodell K. (2008) Invasive exotic plant-bee interactions, in: James R.R., Pitts-Singer T.L. (Eds.), Bee pollination in agroecosystems, Oxford University Press, Oxford, pp. 166-183.

Harder L.D. (1983) Flower handling efficiency of bumble bees: morphological aspects of probing time, Oecologia 57, 274-280.

Heinrich B. (1976) The foraging specialization of individual bumblebees, Ecol. Monogr. 46, 105-128.

Hejda M., Pyšek P. (2006) What is the impact of Impatiens glandulifera on species diversity of invaded riparian vegetation? Biol. Conserv. 132, 143-152.

Hulme P.E., Bremner E.T. (2006) Assessing the impact of Impatiens glandulifera on riparian 
habitats: partitioning diversity components following species removal, J. Appl. Ecol. 43, 43-50.

Inouye D.W. (1980) The effect of proboscis and corolla tube lengths on patterns and rates of flower visitation by bumblebees, Oecologia 45, 197-201.

Johnson S.D., Steiner K.E. (2000) Generalization versus specialization in plant pollination systems, Trends Ecol. Evol. 15, 140-143.

Knight M.E., Martin A.P., Bishop S., Osborne J.L., Hale R.J., Sanderson R.A., Goulson D. (2005) An interspecific comparison of foraging range and nest density of four bumblebee (Bombus) species, Mol. Ecol. 14, 1811-1820.

Könies H., Glavač V. (1979) Über die Konkurrenzfähigkeit des Indischen Springkrautes (Impatiens glandulifera ROYLE) am Fuldaufer bei Kassel, Philippia 4, 47-59.

Levine J.M., Vilà M., D’Antonio C.M., Dukes J.S., Grigulis K., Lavorel S. (2003) Mechanisms underlying the impacts of exotic plant invasions, Proc. R. Soc. B-Biol. Sci. 270, 775-781.

Lopezaraiza-Mikel M.E. (2006) The impact of alien species on native pollination systems, $\mathrm{PhD}$ thesis, University of Bristol, Bristol.

Lopezaraiza-Mikel M.E., Hayes R.B., Whalley M.R., Memmott J. (2007) The impact of an alien plant on a native plant-pollinator network: an experimental approach, Ecol. Lett. 10, 539-550.

Maskell L.C., Firbank L.G., Thompson K., Bullock J.M., Smart S.M. (2006) Interactions between non-native plant species and the floristic composition of common habitats, J. Ecol. 94, 1052-1060.

Memmott J., Waser N.M. (2002) Integration of alien plants into a native flower-pollinator visitation web, Proc. R. Soc. B-Biol. Sci. 269, 2395-2399.

Minitab (2000) MINITAB $^{\text {TM }}$ Statistical Software for Windows, Release 13.30, State College, PA, USA.

Moragues E., Traveset A. (2005) Effect of Carpobrotus spp. on the pollination success of native plant species of the Balearic Islands, Biol. Conserv. 122, 611-619.

Morales C.L., Aizen M.A. (2006) Invasive mutualisms and the structure of plant-pollinator interactions in the temperate forests of north-west Patagonia, Argentina, J. Ecol. 94, 171-180.

Naiman R.J., Décamps H. (1997) The ecology of interfaces: riparian zones, Annu. Rev. Ecol. Syst. 28, 621-658.

Parker I.M. (1997) Pollinator limitation of Cytisus scoparius (Scotch Broom), an invasive exotic shrub, Ecology 78, 1457-1470.

Parker I.M., Haubensak K.A. (2002) Comparative pollinator limitation of two non-native shrubs: do mutualisms influence invasions? Oecologia 130, 250 258.
Perrins J., Fitter A., Williamson M. (1993) Population biology and rates of invasion of three introduced Impatiens species in the British Isles, J. Biogeogr. 20, 33-44.

Proctor M., Yeo P., Lack A. (1996) The natural history of pollination, Timber Press, Portland, Oregon.

Prowse A., Goodridge F. (2000) Pollinator visitation rates of Impatiens glandulifera and other native riparian vegetation, Aspect. Appl. Biol. 58, 249 254.

Prýs-Jones O.E., Corbet S.A. (1991) Bumblebees, Richmond Publishing Slough.

Pyšek P., Prach K. (1993) Plant invasions and the role of riparian habitats - a comparison of four species alien to central Europe, J. Biogeogr. 20, 413-420.

Pyšek P., Prach K. (1995) Invasion dynamics of Impatiens glandulifera - a century of spreading reconstructed, Biol. Conserv. 74, 41-48.

Rathcke B. (1983) Competition and facilitation among plants for pollinators, in: Real L. (Ed.), Pollination biology, Academic Press, Inc., London, pp. 305329.

Reynolds S.C.P. (2002) A catalogue of alien plants in Ireland, National Botanic Gardens, Glasnevin, Dublin.

Richardson D.M., Allsopp N., D’Antonio C.M., Milton S.J., Rejmánek M. (2000) Plant invasions - the role of mutualisms, Biol. Rev. 75, 65-93.

Sala O.E., Chapin F.S., Armesto J.J., Berlow E., Bloomfield J., Dirzo R., Huber-Sanwald E., Hünneke L.F., Jackson R.B., Kinzig A., Leemans R., Lodge D.M., Mooney H.A., Österheld M., Poff N.L., Sykes M.T., Walker B.H., Walker M., Wall D.H. (2000) Biodiversity - global biodiversity scenarios for the year 2100, Science 287, 1770-1774.

Schürkens S., Chittka L. (2001) The significance of the invasive crucifer species Bunias orientalis (Brassicaceae) as a nectar source for central European insects, Entomol. Gen. 25, 115-120.

Showler K. (1989) The Himalayan balsam in Britain - an undervalued source of nectar, Bee World 70, 130-131.

Southwood T.R.E., Henderson P.A. (2000) Ecological methods, Oxford Blackwell Science, Oxford.

Sowig P. (1989) Effects of flowering plants patch size on species composition of pollinator communities, foraging strategies, and resource partitioning in bumblebees (Hymenoptera, Apidae), Oecologia 78, 550-558.

Starý P., Tkalců B. (1998) Bumble-bees (Hym., Bombidae) associated with the expansive touchme-not, Impatiens glandulifera in wetland biocoridors, Anz. Schädl. Schädl. Pflanzenschutz, Umweltschutz 71, 85-87.

Stout J.C., Parnell J.A.N., Arroyo J., Crowe T.P. (2006) Pollination ecology and seed production of 
Rhododendron ponticum in native and exotic habitats, Biodivers. Conserv. 15, 755-777.

Titze A. (2000) The efficiency of insect pollination of the neophyte Impatiens glandulifera (Balsaminaceae), Nord. J. Bot. 20, 33-42.

Traveset A., Richardson D.M. (2006) Biological invasions as disruptors of plant reproductive mutualisms, Trends Ecol. Evol. 21, 208-216.
Underwood A.J. (1997) Experiments in ecology: their logical design and interpretation using analysis of variance, Cambridge University Press, Cambridge.

Vitousek P.M., D'Antonio C.M., Loope L.L., Rejmánek M., Westbrooks R. (1997) Introduced species: a significant component of human-caused global change, New Zeal. J. Ecol. 21, 1-16. 